\title{
Analisis Kinerja EIGRPdan OSPF pada Topologi Ring dan Mesh
}

\section{DWI ARYANTA, ARSYAD RAMADHAN DARLIS, DI MAS PRI YAMBODHO}

\author{
Jurusan Teknik Elektro Institut Teknologi Nasional Bandung \\ Email: dwiaryanta@gmail.com
}

\begin{abstract}
ABSTRAK
EIGRP (Enhanced Interior Gateway Routing Protocol) dan OSPF (Open Shortest Path Fisrt) adalah routing protokol yang banyak digunakan pada suatu jaringan komputer. EIGRP hanya dapat digunakan pada perangkat Merk CISCO, sedangkan OSPF dapat digunakan pada semua merk jaringan. Pada penelitian ini dibandingkan delay dan rute dari kedua routing protokol yang diimplementasikan pada topologi Ring dan Mesh. Cisco Packet Tracer 5.3 digunakan untuk mensimulasikan kedua routing protokol ini. Skenario pertama adalah perancangan jaringan kemudian dilakukan pengujian waktu delay 100 kali dalam 5 kasus. Skenario kedua dilakukan pengujian trace route untuk mengetahui jalur yang dilewati paket data lalu memutus link utama. Pada skenario kedua juga dilakukan perbandingan nilai metric dan cost hasil simulasi dengan perhitungan rumus. Skenario ketiga dilakukan pengujian waktu konvergensi untuk setiap routing protokol pada setiap topologi. Hasilnya EIGRP lebih cepat $386 \mu \mathrm{s}$ daripada OSPF untuk topologi Ring sedangkan OSPF lebih cepat $453 \mu$ s daripada EIGRP untuk topologi Mesh. Hasil trace route menunjukan rute yang dipilih oleh routing protokol yaitu nilai metric dan cost yang terkecil. Waktu konvergensi ratarata topologi Ring pada EIGRP sebesar 12,75 detik dan 34,5 detik pada OSPF sedangkan topologi Mesh di EIGRP sebesar 13 detik dan 35,25 detik di OSPF.
\end{abstract}

Kata Kunci : EIGRP, OSPF, Packet Tracer 5.3, Ring, Mesh, Konvergensi

\begin{abstract}
EIGRP (Enhanced Interior Gateway Routing Protocol) and OSPF (Open Shortest Path Fisrt) is the routing protocol that is widely used in a computer network. EIGRP can only be used on devices Brand CISCO, while OSPF can be used on all brands of network. In this study comparison of both the delay and the routing protocol implemented on Ring and Mesh topology. Cisco Packet Tracer 5.3 is used to simulate both the routing protocol. The first scenario is the design of the network and then do the test of time delay 100 times in 5 cases. The second scenario tested trace route to determine the path of the data packet and then disconnect the main link. In the second scenario also conducted a cost comparison of metrics and the simulation results with the calculation formula. The third scenario testing time for each routing protocol convergence on any topology. The result EIGRP faster than 386 microseconds for a ring topology while OSPF OSPF 453 microseconds faster than EIGRP for Mesh topology. The results showed trace route chosen by the routing protocol metric value and cost is the smallest. Average convergence time in the EIGRP topology Ring of 12.75 seconds and 34.5 seconds, while the Mesh topology in an OSPF EIGRP for 13 seconds and 35.25 seconds in OSPF.
\end{abstract}

Keywords : EIGRP,OSPF, Packet Tracer 5.3, Ring, Mesh, Convergence 


\section{PENDAhUluAN}

Pada saat ini, teknologi telekomunikasi menjadi salah satu kebutuhan yang sangat penting bagi kebanyakan orang di dunia. Hal inilah yang mendasari terciptanya teknologi informasi. Jaringan komputer merupakan sekumpulan komputer berjumlah banyak yang terpisah-pisah dalam hal posisi, akan tetapi saling berhubungan dalam melaksanakan tugasnya. Misalnya dua buah komputer dapat dikatakan terkoneksi bila keduanya dapat saling bertukar informasi.(I wan, 2012)

Komunikasi data merupakan bangunan vital dari suatu masyarakat informasi karena sistem ini menyediakan infrastruktur yang memungkinkan komputer-komputer berkomunikasi satu sama lain (Ferdian, 2011)

Agung telah melakukan implementasi jaringan Fast Ethernet menggunakan OSPF dan EIGRP di PLN kota Palembang disimpulkan bahwa EIGRP dan OSPF layak dijadikan routing protocol untuk backbone jaringan PLN di kota Palembang dengan melihat uji coba transfer file berkecepatan 5688,3 kbps untuk EIGRP dan 5589,6 kbps untuk OSPF. (Agung, 2007)

Selain itu implementasi penelitian jaringan menggunakan Software OPNET juga telah dilakukan untuk membuat simulasi EIGRP dan OSPF routing protocol dengan menganalisa konvergensi waktu, variasi paket delay, dan packet loss. Hasil dari penelitian tersebut adalah EIGRP lebih cepat untuk dijadikan routing protokol. (Nazrul M, 2010)

P. Ramya juga telah mengimplementasikan routing protokol OSPF menggunakan router CISCO 2800 untuk membandingkannya dengan routing protokol Routing Information Protocol (RIP). Hasilnya OSPF memberikan beberapa kelebihan yaitu OSPF tidak terpengaruhi oleh kelas IP Address, update data router setiap 30 detik, dan dapat dihubungkan dengan semua routing protokol. (P. Ramya, 2012)

Penelitian ini bertujuan untuk mengetahui topologi yang terbaik pada masing-masing routing protokol. Dikarenakan setiap routing protokol mempunyai sifat yang berbeda-beda maka dilakukan penelitian menggunakan routing protokol OSPF dan EIGRP yang diuji melalui simulasi menggunakan software CISCO Packet Tracer 5.3. Empat buah router akan di konfigurasi menggunakan topologi Ring dan Mesh dengan media kabel serial untuk menghubungkan antar router dan kabel Fast Ethernet jenis Straight-Through untuk menghubungkan router ke switch dan menghubungkan switch ke PC (Personal Computer), lalu diuji pengetesan PING untuk mengetahui waktu yang ditempuh untuk pengiriman data, trace route untuk mengetahui jalur mana saja yang dilewati oleh packet data. Pada simulasi ini juga akan diputus salah satu link yang biasa dilewati untuk mengetahui jalur mana yang akan dilewati setelah adanya pemutusan link. Selain itu juga akan dibandingkan parameter Metric dan Cost pada simulasi dengan perhitungan rumus untuk mengetahui kebenaran hasil simulasi

\section{METODOLOGI}

\subsection{Perancangan J aringan}

Pada penelitian ini software untuk melakukan simulasi menggunakan Cisco Packet Tracer Versi 5.3. Dalam penelitian ini dijelaskan cara perancangan sistem dan konfigurasi simulasi komunikasi data dalam jaringan berdasarkan topologi Ring dan Mesh dengan menggunakan Routing protocol EIGRP dan OSPF. Gambar 1 merupakan flowchart dari uji performansi: 


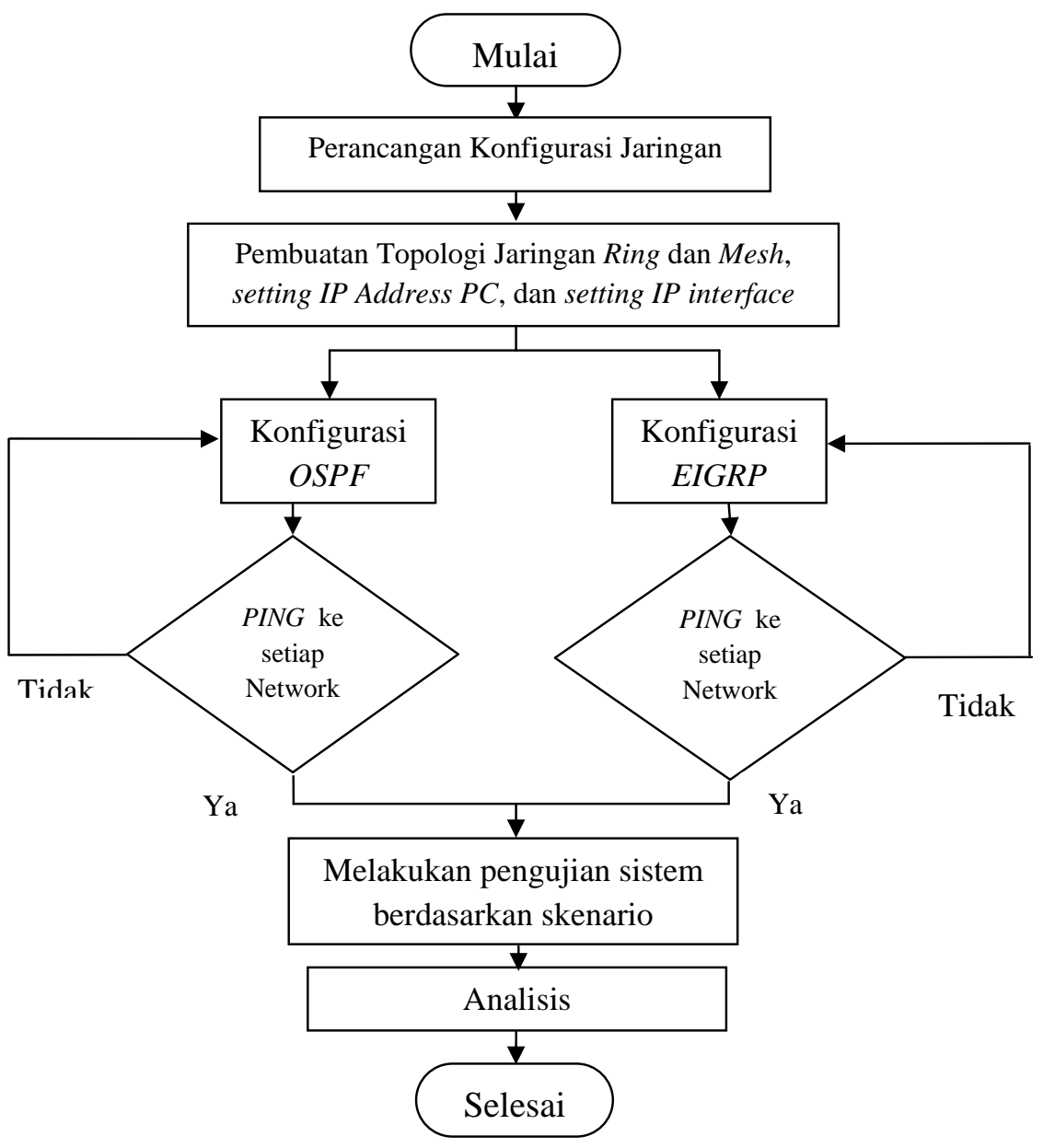

Gambar 1. Flowchart perancangan jaringan

Gambar 1 menunjukkan tahapan dalam perancangan dan simulasi kinerja EIGRP dan OSPF pada topologi Ring dan Mesh. Simulasi ini dilakukan pada software Packet Tracer 5.3. Dimulai dengan mengkonfigurasi jaringan lalu pembuatan topologi jaringan yaitu topologi Ring dan topologi Mesh, setting IP Address, dan setting IP pada setiap interfacenya. Masingmasing topologi dikonfigurasi oleh routing protokol EIGRP dan OSPF. Setelah melakukan konfigurasi routing protokol, pada setiap topologi dan routing protokolnya dilakukan tes PING ke setiap $P C$ yang ada. Setelah berhasil dilakukan pengujian sistem berdasarkan skenario selanjutnya dilakukan analisis.

\subsection{Topologi Jaringan}

Topologi yang digunakan pada simulasi ini adalah topologi Ring dan topologi Mesh dengan menggunakan masing-masing 4 buah router, 4 buah switch dan 8 buah $P C$ untuk setiap topologi dan routing protokol. Gambar 2 berikut merupakan gambar topologi Ring yang digunakan untuk routing protokol EIGRP dan OSPF: dalam routing tersebut terdapat 4 buah router, 4 buah switch dan 8 buah $P C$ dengan 4 buah kabel serial untuk menghubungkan antar routernya 


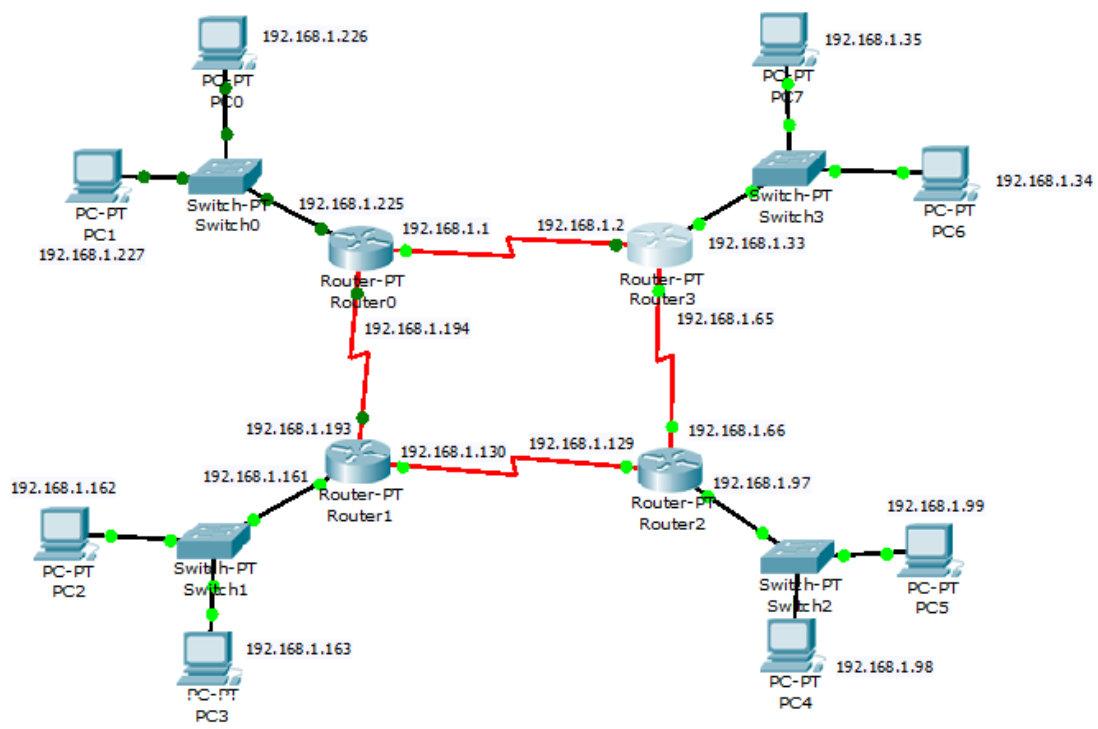

\section{Gambar 2. Perancangan Topologi Ring}

Gambar 3 berikut merupakan gambar topologi Ring yang digunakan untuk routing protokol EIGRP dan OSPF: dalam routing tersebut terdapat 4 buah router, 4 buah switch dan 8 buah $P C$ dengan 6 buah kabel serial untuk menghubungkan antar routemya

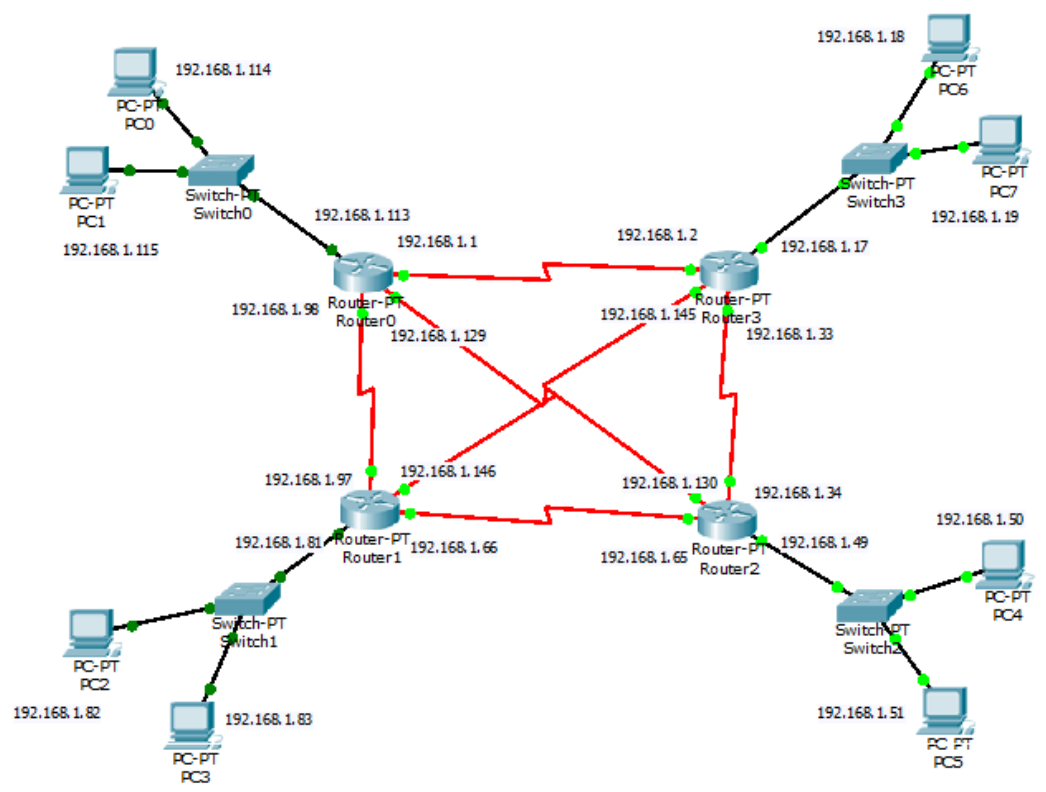

\section{Gambar 3. Perancangan Topologi Mesh}

\subsection{Perhitungan IP Address}

Pada tahap ini dilakukan subnetting berdasarkan banyaknya jaringan yang diperlukan sehingga tidak membuang terlalu banyak Network Address. 192.168.1.0 merupakan Network Address yang digunakan dalam jaringan ini. Berikut adalah perhitungan IP Address berdasarkan teknik Subnetting IPV4: 
a. Topologi Ring

$2^{n} \geq x, n$ merupakan jumlah biner 1 pada subnet mask yang harus ditambahkan agar melebihi atau sama dengan jumlah jaringan yang dibutuhkan sedangkan $\mathrm{x}$ adalah jumlah banyaknya subnet yang dibutuhkan pada suatu jaringan sehingga persamaannya menjadi:

$$
\begin{gathered}
2^{n} \geq x \\
2^{n} \geq 8 \\
\text { Jika } n=3 \text { maka, } \\
8 \geq 8
\end{gathered}
$$

Dengan menambahkan 3 bit di subnet mask 255.255.255.0/24 maka akan sebagaimana ditunjukkan oleh tabel 1:

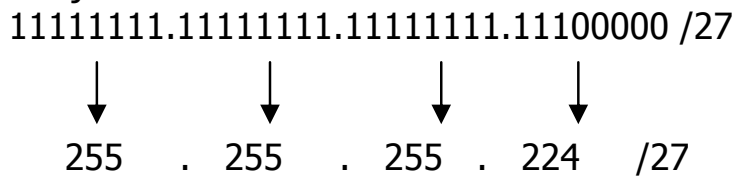

Jumlah total host 256 dikurangi 224 dari jumlah perhitungan diatas menjadi selisih atau range IP Address yang bisa digunakan untuk setiap Subnet, $256-224=32$

Subnetting menjadi 8 subnet dan 29 Host baru di setiap Subnet-nya menjadi:

Tabel 1. Pembagian Address pada topologi Ring

\begin{tabular}{|c|c|c|c|}
\hline $\begin{array}{c}\text { Nomor } \\
\text { Subnet }\end{array}$ & IP Address yang tersedia & $\begin{array}{c}\text { Network } \\
\text { Address }\end{array}$ & Broadcast Address \\
\hline SN1 & $192.168 .1 .0-192.168 .1 .31$ & 192.168 .1 .0 & 192.168 .1 .31 \\
\hline SN2 & $192.168 .1 .32-192.168 .1 .63$ & 192.168 .1 .32 & 192.168 .1 .63 \\
\hline SN3 & $192.168 .1 .64-192.168 .1 .95$ & 192.168 .1 .64 & 192.168 .1 .95 \\
\hline SN4 & $192.168 .1 .96-192.168 .1 .127$ & 192.168 .1 .96 & 192.168 .1 .127 \\
\hline SN5 & $192.168 .1 .128-192.168 .159$ & 192.168 .1 .128 & 192.168 .1 .159 \\
\hline SN6 & $192.168 .1 .160-192.168 .1 .191$ & 192.168 .1 .160 & 192.168 .1 .191 \\
\hline SN7 & $192.168 .1 .192-192.168 .1 .223$ & 192.168 .1 .192 & 192.168 .1 .223 \\
\hline SN8 & $192.168 .1 .224-192.168 .1 .255$ & 192.168 .1 .224 & 192.168 .1 .255 \\
\hline
\end{tabular}

b. Topologi Mesh

$$
\begin{gathered}
2^{n} \geq x \\
2^{n} \geq 10 \\
\text { Jika } n=4 \text { maka, } \\
16 \geq 10
\end{gathered}
$$

Dengan menambahkan 3 bit di subnet mask 255.255.255.0/24 maka akan menjadi:

$11111111.11111111 .11111111 .11100000 / 28$

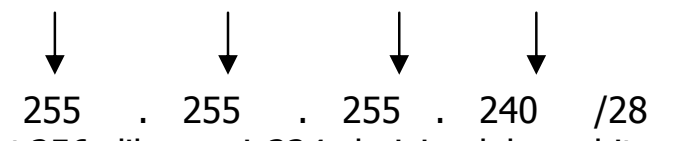

Jumlah total host 256 dikurangi 224 dari jumlah perhitungan diatas menjadi selisih atau range IP Address yang bisa digunakan untuk setiap Subnet,

$256-240=16$

Subnetting menjadi 16 subnet dan 14 Host baru di setiap Subnet-nya menjadi sebagaimana ditunjukkan oleh tabel 2: 
Tabel 2. Pembagian Address pada Topologi Mesh

\begin{tabular}{|c|c|c|c|}
\hline $\begin{array}{c}\text { Nomor } \\
\text { Subnet }\end{array}$ & IP Address yang tersedia & $\begin{array}{c}\text { Network } \\
\text { Address }\end{array}$ & $\begin{array}{c}\text { Broadcast } \\
\text { Address }\end{array}$ \\
\hline SN1 & $192.168 .1 .0-192.168 .1 .15$ & 192.168 .1 .0 & 192.168 .1 .15 \\
\hline SN2 & $192.168 .1 .16-192.168 .1 .31$ & 192.168 .1 .16 & 192.168 .1 .31 \\
\hline SN3 & $192.168 .1 .32-192.168 .1 .47$ & 192.168 .1 .32 & 192.168 .1 .47 \\
\hline SN4 & $192.168 .1 .48-192.168 .1 .63$ & 192.168 .1 .48 & 192.168 .1 .63 \\
\hline SN5 & $192.168 .1 .64-192.168 .79$ & 192.168 .1 .64 & 192.168 .1 .79 \\
\hline SN6 & $192.168 .1 .80-192.168 .1 .95$ & 192.168 .1 .80 & 192.168 .1 .95 \\
\hline SN7 & $192.168 .1 .96-192.168 .1 .111$ & 192.168 .1 .96 & 192.168 .1 .111 \\
\hline SN8 & $192.168 .1 .112-192.168 .1 .127$ & 192.168 .1 .112 & 192.168 .1 .127 \\
\hline SN9 & $192.168 .1 .128-192.168 .1 .143$ & 192.168 .1 .128 & 192.168 .1 .143 \\
\hline SN10 & $192.168 .1 .144-192.168 .1 .159$ & 192.168 .1 .144 & 192.168 .1 .159 \\
\hline SN11 & $192.168 .1 .160-192.168 .1 .175$ & 192.168 .1 .160 & 192.168 .1 .175 \\
\hline SN12 & $192.168 .1 .176-192.168 .1 .191$ & 192.168 .1 .176 & 192.168 .1 .191 \\
\hline SN13 & $192.168 .1 .192-192.168 .1 .207$ & 192.168 .1 .192 & 192.168 .1 .207 \\
\hline SN14 & $192.168 .1 .208-192.168 .1 .223$ & 192.168 .1 .208 & 192.168 .1 .223 \\
\hline SN15 & $192.168 .1 .224-192.168 .1 .239$ & 192.168 .1 .224 & 192.168 .1 .239 \\
\hline SN16 & $192.168 .1 .240-192.168 .1 .255$ & 192.168 .1 .240 & 192.168 .1 .255 \\
\hline
\end{tabular}

\section{HASI L SI MULASI DAN PEMBAHASAN}

\subsection{Skenario Pengujian}

Hasil simulasi yang didapatkan dari penelitian ini berdasarkan penggunaan workspace dan realtime simulation pada Cisco Packet Tracer 5.3 untuk setiap routing protokol.

Skenario pengujian dilakukan dengan cara sebagai berikut:

1. Mengamati waktu delay pengiriman paket data dari $P C$ ke $P C$ lain pada saat traffic sedang sibuk.

2. Mengamati trace route atau jalur yang biasa dilewati paket data saat pengiriman, lalu memutus link yang biasa dilewati paket data untuk mengetahui perbedaan rute yang dilewati.

Hasil pengujian pada simulasi ini akan dijelaskan sebagai berikut

\subsubsection{Skenario Pertama}

Pengujian skenario pertama dilakukan dengan cara pengiriman paket Internet Control Message Protocol (ICMP) pada saat traffic sedang sibuk sebanyak lima kasus dan setiap kasusnya di ulang sebanyak lima kali percobaan, untuk meningkatkan traffic pada jaringan ditambahkan 4 paket ICMP dengan kondisi yang sama untuk setiap kasusnya. 5 kasus yang disimulasikan tersebut berlaku untuk topologi Ring dan Mesh.

Skenario pengiriman data dari $P C$ ke $P C$ akan ditampilkan dalam Tabel 3 berikut ini.

Tabel 3. Skenario pengiriman paket data

\begin{tabular}{|c|c|c|c|c|c|c|c|c|c|}
\hline \multicolumn{2}{|c|}{ Kasus 1 } & \multicolumn{2}{c|}{ Kasus 2 } & \multicolumn{2}{c|}{ Kasus 3 } & \multicolumn{2}{c|}{ Kasus 4 } & \multicolumn{2}{c|}{ Kasus 5 } \\
\hline Pengirim & Penerima & Pengirim & Penerima & Pengirim & Penerima & Pengirim & Penerima & Pengirim & Penerima \\
\hline$P C$ 0 & $P C 5$ & $P C 1$ & $P C 2$ & $P C 2$ & $P C 4$ & $P C 4$ & $P C 7$ & $P C 6$ & $P C 5$ \\
\hline$P C 1$ & $P C 2$ & $P C 2$ & $P C 4$ & $P C 4$ & $P C 7$ & $P C 6$ & $P C 5$ & $P C 0$ & $P C 5$ \\
\hline$P C 2$ & $P C 4$ & $P C 4$ & $P C 7$ & $P C 6$ & $P C 5$ & $P C 0$ & $P C 5$ & $P C 1$ & $P C 2$ \\
\hline$P C 4$ & $P C 7$ & $P C 6$ & $P C 5$ & $P C 0$ & $P C 5$ & $P C 1$ & $P C 2$ & $P C 2$ & $P C 4$ \\
\hline$P C 6$ & $P C 5$ & $P C 0$ & $P C 5$ & $P C 1$ & $P C 2$ & $P C 2$ & $P C 4$ & $P C 4$ & $P C 7$ \\
\hline
\end{tabular}


Paket yang diteliti adalah paket yang pertama dalam Tabel 3 atau baris yang berwarna abuabu. Paket yang lainnya adalah paket yang dikirimkan untuk meningkatkan traffic pada jaringan.

Topologi tersebut diuji menggunakan routing protokol EIGRP dan OSPF. Delay pada hasil pengamatan ini didapatkan dengan cara membagi dua waktu yang dihasilkan dari simulasi. Berdasarkan Tabel $3 \mathrm{Di}$ atas dapat dibuat grafik perbandingan nilai rata-rata delay dengan kasus-kasus digunakan yaitu sebagaimana ditunjukkan oleh Tabel 4:

1. Perbandingan Ring EIGRP dan Ring OSPF

Tabel 4. Nilai Rata-rata Delay Ring EI GRPdan OSPF

\begin{tabular}{|c|c|c|c|c|c|}
\hline \multicolumn{6}{|c|}{ Perbandingan nilai rata-rata delay (detik) } \\
\hline \multirow{2}{*}{ Topologi dan routing protokol } & \multicolumn{5}{|c|}{ Kasus } \\
\cline { 2 - 6 } & $\mathbf{1}$ & $\mathbf{2}$ & $\mathbf{3}$ & $\mathbf{4}$ & $\mathbf{5}$ \\
\hline Ring EI GRP & 0,012505 & 0,01033 & 0,010325 & 0,01008 & 0,010715 \\
\hline Ring OSPF & 0,01305 & 0,01061 & 0,010715 & 0,010405 & 0,011105 \\
\hline
\end{tabular}

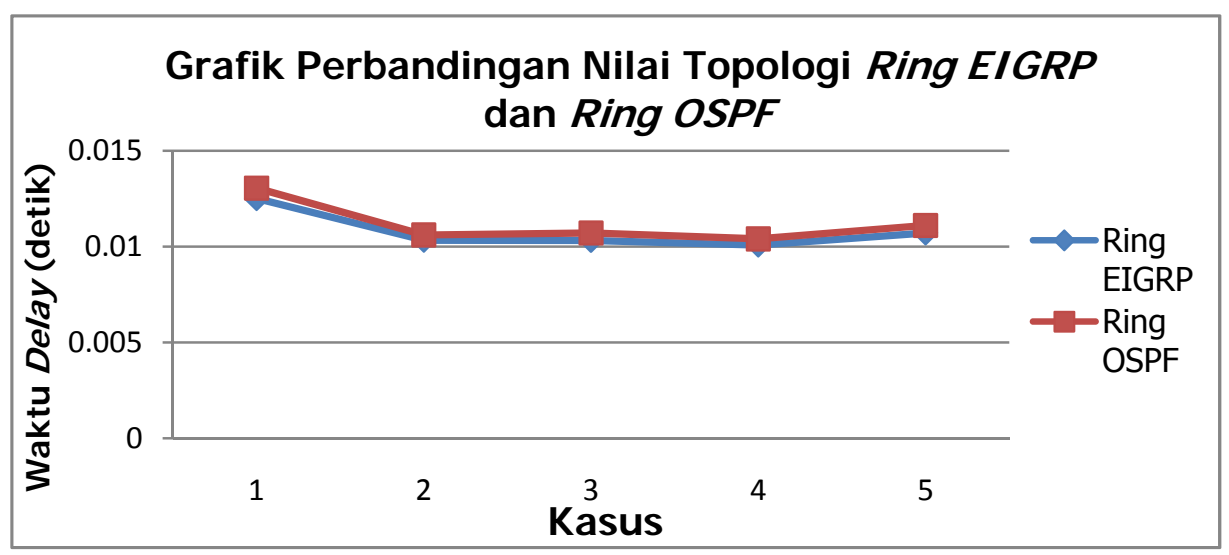

Gambar 4. Grafik Perbandingan Nilai Topologi Ring EI GRPdan Ring OSPF

Jika dirata-ratakan nilai delay tiap routing protokol untuk setiap kasusnya maka didapatkan:

Topologi Ring EIGRP

$$
\begin{aligned}
& \text { delay rata - rata Topologi Ring EIGRP } \\
& \frac{0,012505+0,01033+0,010325+0,01008+0,010715}{5}=0,010791 \text { detik }
\end{aligned}
$$

Topologi Ring OSPF

$$
\begin{aligned}
& \text { delay rata - rata Topologi Ring OSPF } \\
& \frac{0,01305+0,01061+0,010715+0,010405+0,011105}{5}=0,011177 \text { detik }
\end{aligned}
$$

Nilai Ring EIGRP lebih baik 0,000386 detik dibandingkan nilai Ring OSPF. 
2. Perbandingan Mesh EIGRP dan Mesh OSPF

Tabel 5 menunjukan nilai rata-rata delay dengan kasus-kasus digunakan yaitu sebagaimana ditunjukkan oleh Tabel 4:

Tabel 5. Nilai rata-rata delay Mesh EIGRPdan OSPF

\begin{tabular}{|c|c|c|c|c|c|}
\hline \multicolumn{6}{|c|}{ Perbandingan nilai rata-rata delay (detik) } \\
\hline \multirow{2}{*}{ Topologi dan routing protokol } & \multicolumn{5}{|c|}{ Kasus } \\
\cline { 2 - 6 } & $\mathbf{1}$ & $\mathbf{2}$ & $\mathbf{3}$ & $\mathbf{4}$ & $\mathbf{5}$ \\
\hline Mesh EIGRP & 0,013115 & 0,01182 & 0,01231 & 0,010035 & 0,01038 \\
\hline Mesh OSPF & 0,01231 & 0,01082 & 0,01125 & 0,010505 & 0,010825 \\
\hline
\end{tabular}

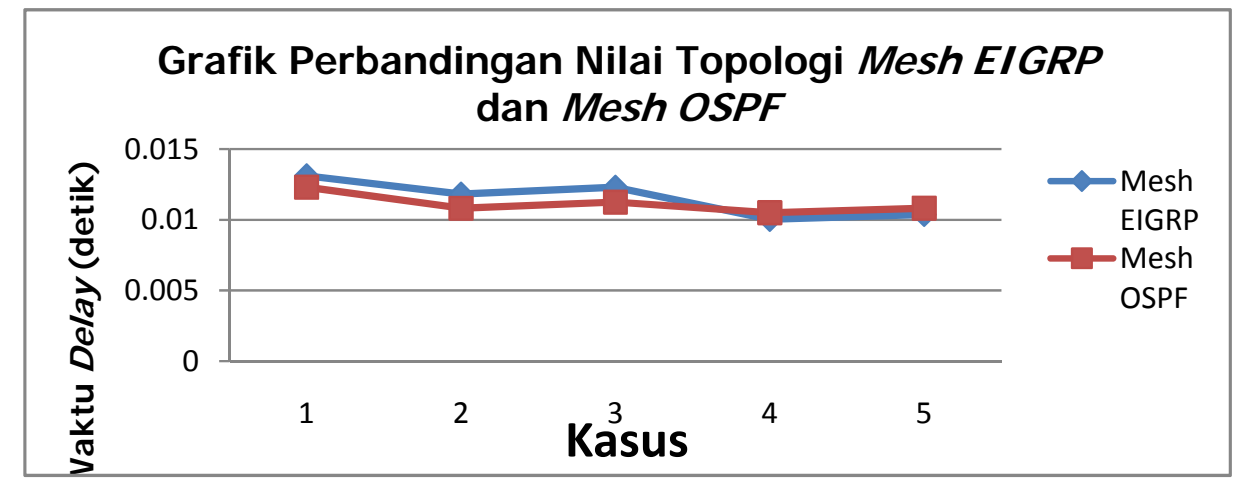

Gambar 5. Grafik Perbandingan Nilai Topologi Mesh EI GRPdan Mesh OSPF

Jika dirata-ratakan nilai delay tiap routing protokol untuk setiap kasusnya maka:

Mesh EIGRP

$$
\begin{aligned}
& \text { delay rata - rata Topologi Mesh EIGRP } \\
& \frac{0,013115+0,01182+0,01231+0,010035+0,01038}{5}=0,011595 \text { detik }
\end{aligned}
$$

Mesh OSPF

$$
\begin{aligned}
& \text { delay rata - rata Topologi Mesh OSPF } \\
& \frac{0,01231+0,01082+0,01125+0,010505+0,010825}{5}=0,011142 \text { detik }
\end{aligned}
$$

Nilai Mesh EIGRP lebih baik 0,000453 detik dibandingkan nilai Mesh OSPF.

\subsubsection{Skenario Kedua}

Pengujian skenario kedua ini dilakukan dengan cara melihat router yang dilewati paket data sebelum pemutusan link, lalu memutuskan beberapa link yang dilewati paket tersebut untuk mengetahui perubahan jalur yang dilewati paket data. 


\section{a. Hasil pengujian skenario kedua sebelum pemutusan link}

1. Topologi Ring EIGRP

Jalur yang dilewati oleh paket ICMP untuk pengiriman dari $P C 0$ ke $P C 5$ adalah $P C 0-$ Switch 0 - Router 0 - Router 3 - Router 2 - Switch 2 - PC 5 . Hal ini disebabkan karena pemilihan jalur pada EIGRP dilakukan oleh parameter nilai metric yang berbeda untuk setiap jalurnya. Nilai Metric dihitung dari total jalur atau interface yang dilewati dari Router sumber ke Router tujuan dengan persamaan sebagai berikut:

$$
\text { metric }=256 *\left(\frac{10^{7}}{\text { minimum bandwidth }}+\frac{\text { total delay }}{10}\right)
$$

Penjelasan lebih lanjut tentang nilai metric akan dijelaskan pada Gambar 6 sebagai berikut.

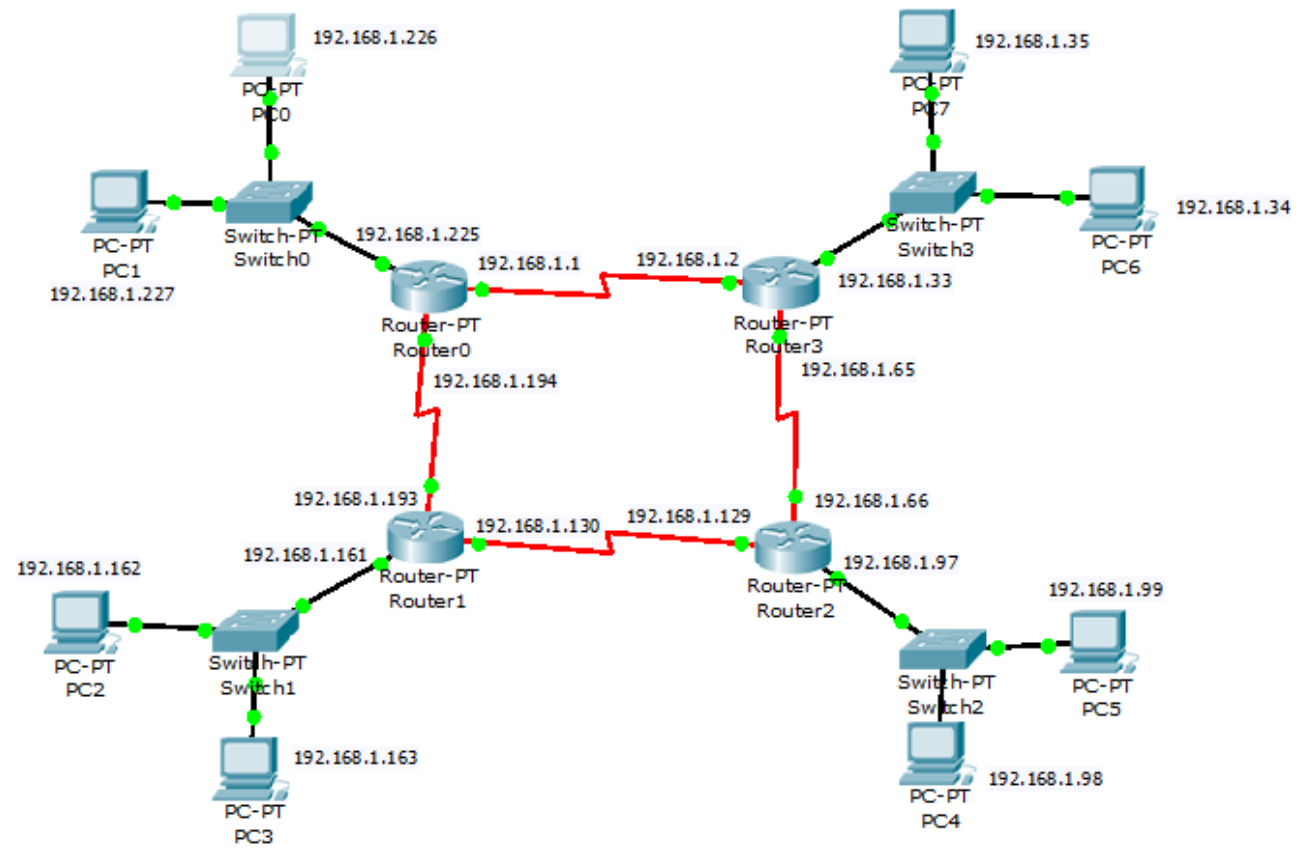

\section{Gambar 6. Rute pengiriman paket dari Router O menuju Network address di Router 2 Topologi Ring EIGRP}

Dari Gambar 6 diatas dapat dilihat jalur pengiriman paket dari Network address di router 0 menuju Network address di Router 2 via Router 3 dengan bandwidth minimum $100 \mathrm{kbps}$, delay interface serial 20000 us dan delay interface fast ethernet $100 \mu \mathrm{s}$. Perhitungan nilai metric-nya adalah sebagai berikut:

$$
\text { metric }=256 *\left(\frac{10^{7}}{100 k b p s}+\frac{(20000 \mu s+20000 \mu s+100 \mu s)}{10}\right)=26626560
$$

Sedangkan jika pengiriman paket dari Network address di router 0 menuju Network address di router 2 via Router 1 dengan bandwidth minimum 50 kbps, delay interface serial 20000 $\mu s$ dan delay interface fast ethernet $100 \mu \mathrm{s}$. Perhitungan nilai metric-nya adalah sebagai berikut: 


$$
\text { metric }=256 *\left(\frac{10^{7}}{50 k b p s}+\frac{(20000 \mu s+20000 \mu s+100 \mu s)}{10}\right)=52226560
$$

Dari perhitungan metric tersebut dapat dibuktikan bahwa paket data akan melewati nilai metric 26626560 yang terkecil untuk mencapai ke tujuan dibandingkan melewati nilai metric yang 52226560 yang lebih besar daripada metric yang lainnya.

\section{Topologi Mesh EIGRP}

Jalur yang dilewati oleh paket ICMP untuk pengiriman dari $P C O$ ke $P C 5$ adalah tersebut adalah PC 0-Switch 0-Router 0-Router 3-Router 2-Switch 2-PC 5. Perhitungan nilai metric-nya adalah sebagaimana Gambar 7 berikut:

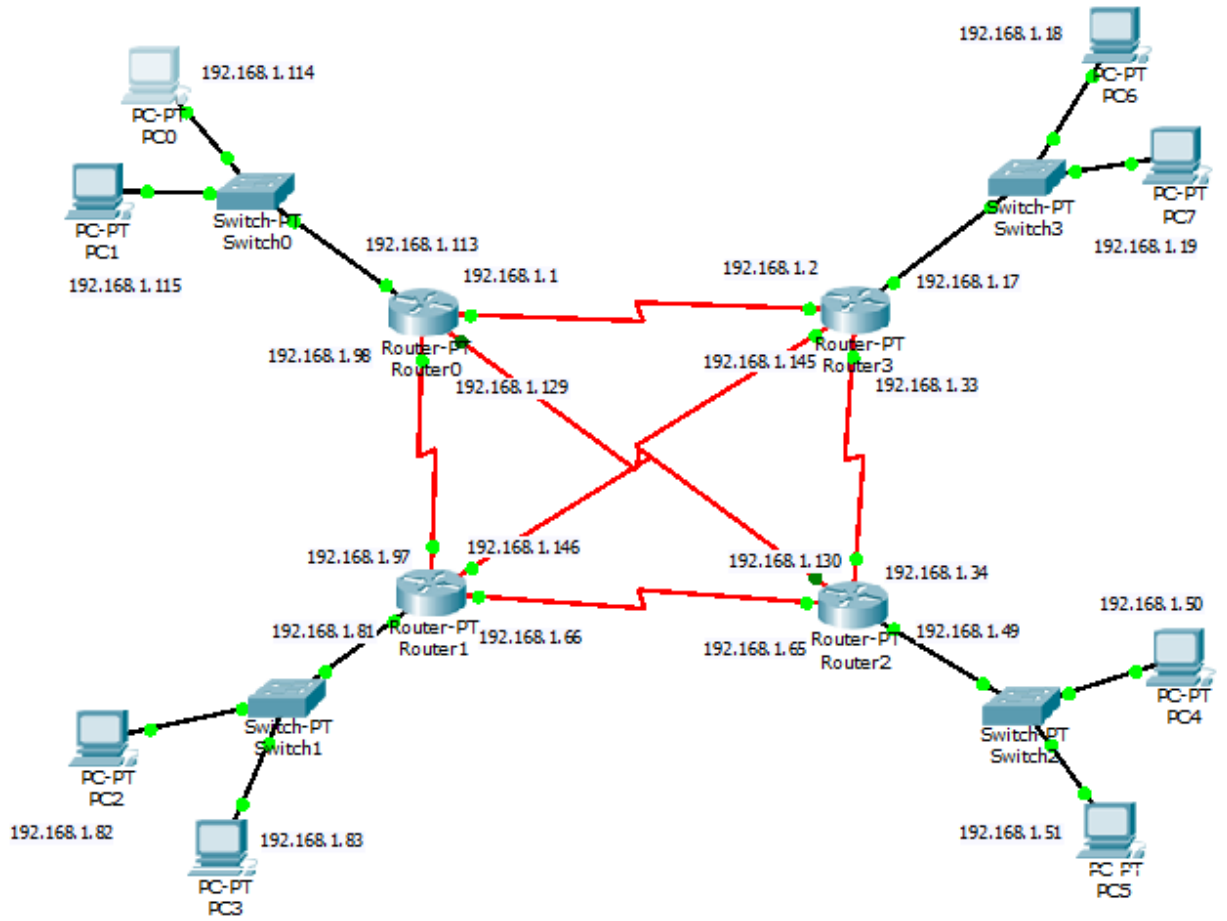

\section{Gambar 7. Rute pengiriman paket dari Router 0 menuju Network address di Router 2} Topologi Mesh EIGRP

Dari Gambar 7 diatas dapat dilihat jalur pengiriman paket dari Network address di router 0 menuju Network address di router 2 via Router 3 dengan bandwidth minimum $100 \mathrm{kbps}$, delay interface serial $20000 \mu \mathrm{s}$ dan delay interface fast ethernet $100 \mu \mathrm{s}$. Perhitungan nilai metric-nya adalah sebagai berikut:

$$
\text { metric }=256 *\left(\frac{10^{7}}{100 \mathrm{kbps}}+\frac{(20000 \mu \mathrm{s}+20000 \mu \mathrm{s}+100 \mu \mathrm{s})}{10}\right)=26626560
$$

Sedangkan jika pengiriman paket dari Network address di router 0 menuju Network address di router 2 via Router 1 dengan bandwidth minimum 25 kbps, delay interface serial 20000 us dan delay interface fast ethernet $100 \mu \mathrm{s}$. Perhitungan nilai metric-nya adalah sebagai berikut:

$$
\text { metric }=256 *\left(\frac{10^{7}}{25 \mathrm{kbps}}+\frac{(20000 \mu \mathrm{s}+20000 \mu \mathrm{s}+100 \mu \mathrm{s})}{10}\right)=103426560
$$


Jika pengiriman paket dari Network address di router 0 langsung menuju Network address di router 2 dengan bandwidth minimum $50 \mathrm{kbps}$, delay interface serial 20000 us dan delay interface fast ethernet $100 \mu \mathrm{s}$. Perhitungan nilai metric-nya adalah sebagai berikut

$$
\text { metric }=256 *\left(\frac{10^{7}}{50 k b p s}+\frac{(20000 \mu s+100 \mu s)}{10}\right)=51714560
$$

Dari perhitungan metric tersebut dapat dibuktikan bahwa paket data akan melewati nilai metric 26626560 yang terkecil untuk mencapai ke tujuan dibandingkan melewati nilai metric 51714560 dan 103426560 yang lebih besar.

3. Topologi Ring OSPF

Jalur yang dilewati oleh paket ICMP untuk pengiriman dari $P C O$ ke $P C 5$ adalah tersebut adalah $P C 0$ - Switch 0 - Router 0 - Router 3 - Router 2 - Switch 2 - PC 5 . Hal ini disebabkan karena pemilihan jalur pada OSPF dilakukan parameter oleh nilai Cost yang berbeda untuk setiap masing-masing jalurnya, nilai Cost dihitung dari masing-masing atau interface yang dilewati dari Router sumber ke Router tujuan dengan persamaan sebagai berikut:

$$
\text { Cost }=\frac{100 \mathrm{Mbps}}{\text { Bandwidth }}
$$

Penjelasan lebih lanjut tentang perhitungan Cost akan dijelaskan pada Gambar 8 sebagai berikut:

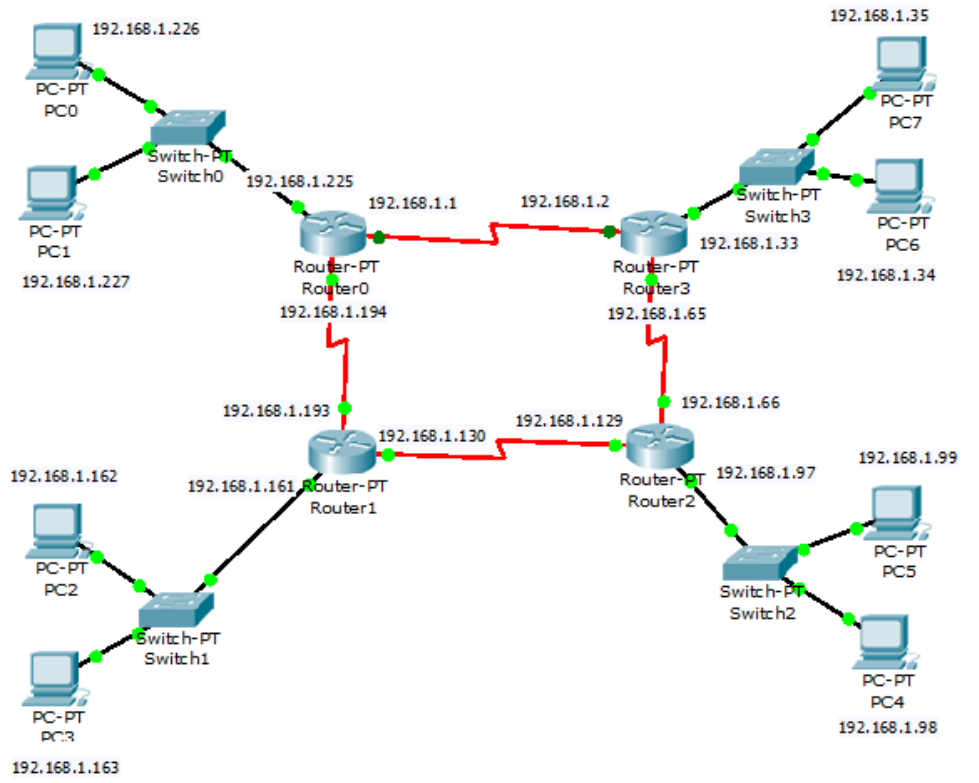

Gambar 8. Rute pengiriman paket dari Router 0 menuju Router 2 Topologi Ring OSPF

Dari Gambar 8 di atas dapat dilihat jalur pengiriman paket dari Network address di router 0 menuju Network address di router 2 via Router 3 dengan bandwidth masing-masing $100 \mathrm{kbps}$, perhitungan nilai Cost-nya adalah sebagai berikut:

$$
\operatorname{Cost}(\text { total })=\frac{100 \mathrm{Mbps}}{100 \mathrm{kbps}}+\frac{100 \mathrm{Mbps}}{100 \mathrm{kbps}}+\frac{100 \mathrm{Mbps}}{100 \mathrm{Mbps}}=2001
$$


Jadi cost interface menuju Router 2 adalah 2001 jika hal ini dapat dibuktikan pada cost hasil simulasi dengan mengetikan "show ip route" yang hasilnya sebagai mana Gaambar 9 berikut:

$$
0 \quad 192.168 .1 .96[110 / 2001] \text { via } 192.168 .1 .2,00: 00: 20 \text {, Serial2/0 }
$$

\section{Gambar 9. Nilai Cost interface dari interface 192.168.1.1 ke interface 192.168.1.97 via Router 3 simulasi Ring OSPF}

Sedangkan jika pengiriman paket dari Network address di Router 0 menuju Network address di router 2 via Router 1 dengan bandwidth masing-masing interface $50 \mathrm{kbps}$, perhitungan nilai cost-nya adalah sebagai berikut:

$$
\operatorname{Cost}(\text { total })=\frac{100 \mathrm{Mbps}}{50 \mathrm{kbps}}+\frac{100 \mathrm{Mbps}}{50 \mathrm{kbps}}+\frac{100 \mathrm{Mbps}}{100 \mathrm{mbps}}=4001
$$

Jadi cost interface menuju Router 2 adalah 4001 hal ini dapat dibuktikan pada cost hasil simulasi dengan mengetikan "show ip route" yang hasilnya sebagaimana Gambar 10 berikut:

$$
0 \quad 192.168 .1 .96[110 / 4001] \text { via } 192.168 .1 .193,00: 00: 00 \text {, Seria13/0 }
$$

\section{Gambar 10. Nilai Cost interface dari interface 192.168.1.194 ke interface 192.168.1.97 via Router 1 simulasi Ring OSPF}

Dari perhitungan Cost tersebut dapat dibuktikan bahwa paket data akan melewati nilai Cost yang terkecil yaitu 2001 untuk mencapai ke tujuan daripada melewati cost yang lebih besar yang bernilai 4001.

4. Topologi Mesh OSPF

Jalur yang dilewati oleh paket ICMP untuk pengiriman dari $P C 0$ ke $P C 5$ adalah tersebut adalah PC 0 - Switch 0 - Router 0 - (Router 3-Router 2) / (Router 2) - Switch 2 $P C 5$ Perhitungan nilai cost-nya adalah sebagaimana Gambar 11 berikut:

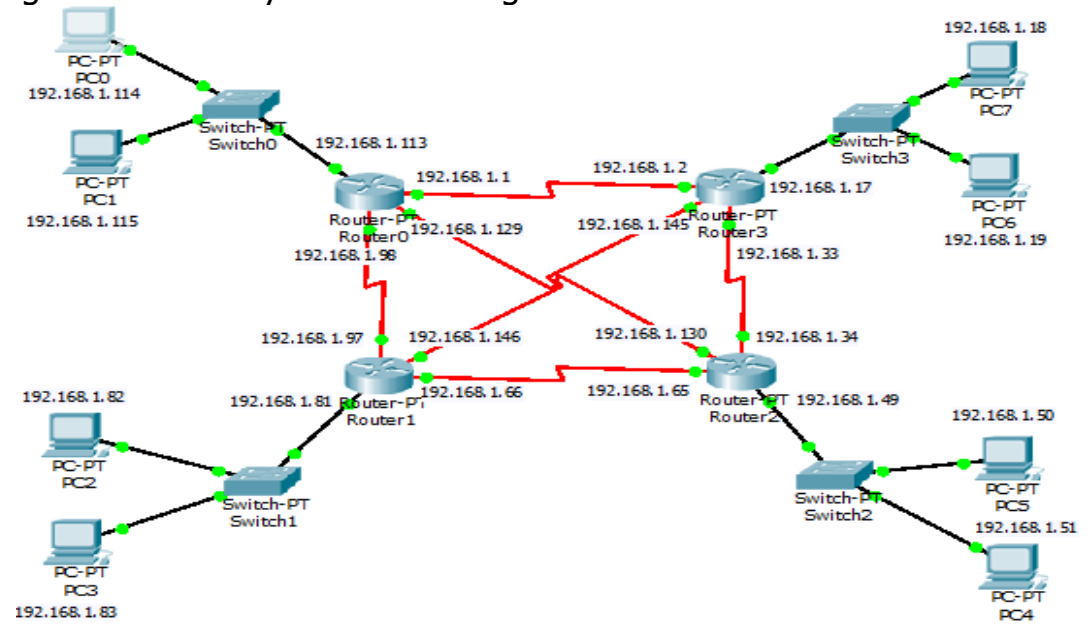

\section{Gambar 11. Rute pengiriman paket dari Router 0 menuju Network address di Router 2 Topologi Mesh OSPF}

Dari Gambar 11 diatas dapat dilihat jalur pengiriman paket dari Network address di router 0 menuju Network address di router 2 via Router 3 dengan bandwidth masing-masing 100 kbps, perhitungan nilai Cost-nya adalah sebagai berikut:

$$
\operatorname{Cost}(\text { total })=\frac{100 \mathrm{Mbps}}{100 \mathrm{kbps}}+\frac{100 \mathrm{Mbps}}{100 \mathrm{kbps}}+\frac{100 \mathrm{Mbps}}{100 \mathrm{Mbps}}=2001
$$


Jadi cost interface menuju Router 2 adalah 2001 hal ini dapat dibuktikan pada cost hasil simulasi dengan mengetikan "show ip route" yang hasilnya sebagaimana Gambar 12 berikut:

o 192.168.1.48 [110/2001] via 192.168.1.130, 00:03:33, Seria16/0

Gambar 12. Nilai Cost interface 192.168.1.1 ke interface 192.168.1.49 via Router 3 dari simulasi Mesh OSPF

Sedangkan jika pengiriman paket dari Network address di router 0 menuju Network address di router 2 via Router 1 dengan bandwidth masing-masing interface $25 \mathrm{kbps}$, perhitungan nilai cost-nya adalah sebagai berikut:

$$
\operatorname{Cost}(\text { total })=\frac{100 \mathrm{Mbps}}{25 \mathrm{kbps}}+\frac{100 \mathrm{Mbps}}{25 \mathrm{kbps}}+\frac{100 \mathrm{Mbps}}{100 \mathrm{Mbps}}=8001
$$

Jadi cost interface menuju Router 2 adalah hal ini dapat dibuktikan pada cost hasil simulasi dengan mengetikan "show ip route" yang hasilnya sebagaimana Gambar 13 berikut:

$0 \quad 192.168 .1 .48[110 / 8001]$ via 192.168.1.97, 00:00:28, Serial3/0

Gambar 13. Nilai Cost Cost interface 192.168.1.98 ke interface 192.168.1.49 via Router 1 dari simulasi Mesh OSPF

Jika pengiriman paket dari Network address di router 0 langsung menuju Network address di router 2 dengan bandwidth $50 \mathrm{kbps}$, perhitungan nilai cost-nya adalah sebagai berikut:

$$
\operatorname{Cost}(\text { total })=\frac{100 \mathrm{Mbps}}{50 \mathrm{kbps}}+\frac{100 \mathrm{Mbps}}{100 \mathrm{Mbps}}=2001
$$

Jadi cost interface menuju Router 2 adalah 2001 hal ini dapat dibuktikan pada cost hasil simulasi dengan mengetikan "show ip route" yang hasilnya sebagaimana Gambar 14 berikut:

$$
0 \quad 192.168 .1 .48[110 / 2001] \text { via 192.168.1.130, 00:00:39, Seria16/0 }
$$

Gambar 14. Nilai Cost Cost interface 192.168.1.129 ke interface 192.168.1.49 dari simulasi Mesh OSPF

Dari perhitungan Cost tersebut dapat dibuktikan bahwa paket data akan melewati nilai Cost yang terkecil yaitu 2001 untuk mencapai ke tujuan daripada melewati cost yang lebih besar yang bernilai 4001. Pada percobaan OSPF Mesh ini terdapat 2 link dengan cost yang sama yaitu 2001 karena OSPF bersifat link state sehingga OSPF dapat memilih salah satu diantara keduanya, jalur yang dipilih tidak tetap diantara kedua link tersebut.

\section{b. Hasil pengujian skenario kedua setelah pemutusan link}

Setelah mengetahui jalur yang dilewati paket data ICMP pada perintah PING lalu jalur yang biasa dilewati diputus untuk mengetahui Jalur backup yang dimiliki masing-masing Routing protokol pada setiap topologi. Jalur yang diputus adalah Jalur yang menghubungkan antara Router 0 ke Router 3 . Hasilnya adalah sebagai berikut:

1. Topologi Ring EIGRP

Setelah link diputuskan rute yang dilewati dari $P C 0$ ke $P C 5$ adalah $P C 0$ - Switch 0 Router 0 - Router 1 - Router 2-Switch 2-PC 5. Paket data akan melewati nilai metric 52226560. hal ini sesuai dengan hasil perhitungan metric sebelumnya.

2. Topologi Mesh EIGRP

Setelah link diputuskan rute yang dilewati dari $P C 0$ ke $P C 5$ adalah $P C 0$ - Switch $0-$ Router 0- Router 2 - Switch 2-PC 5. Paket data akan melewati nilai metric kedua terkecil dan juga link terpendek dari seluruh link yang ada yaitu 51714560 . Hal ini sesuai dengan hasil perhitungan metric sebelumnya dimana paket data tidak akan melewati metric yang lebih besar yaitu 103426560 . 


\section{Topologi Ring OSPF}

Setelah link diputuskan rute yang dilewati dari $P C 0$ ke $P C 5$ adalah $P C 0$ - Switch 0 Router 0 - Router 1 - Router 2 - Switch 2-PC 5. Paket data akan melewati nilai cost 4001. Hal ini sesuai dengan hasil perhitungan cost sebelumnya.

4. Topologi Mesh OSPF

Setelah link diputuskan rute yang dilewati dari $P C 0$ ke $P C 5$ adalah tetap yaitu $P C 0-$ Switch 0 - Router 0-Router 2-Switch 2-PC 5. Paket data akan melewati nilai cost kedua terkecil dan juga link terpendek dari seluruh link yang ada yaitu 2001. Hal ini sesuai dengan hasil perhitungan cost sebelumnya dimana paket data tidak akan melewati cost yang lebih besar yaitu 4001.

\subsubsection{Waktu Konvergensi}

Pada skenario ketiga ini akan diteliti waktu konvergensi yaitu waktu untuk setiap router mendapatkan informasi dari routeryang lain dan siap untuk mengirimkan paket data.

a. Waktu konvergensi Topologi Ring EIGRP

Untuk mengetahui waktu konvergensi Ring EIGRP dapat dilakukan dengan cara perintah "show ip EIGRP neighbors" pada CLI Command di setiap routemya yang hasilnya seperti Gambar 15 berikut:

\begin{tabular}{|c|c|c|c|c|c|c|c|c|}
\hline $\mathrm{H}$ & Address & Interface & $\begin{array}{l}\mathrm{H} \circ \mathrm{l} \\
\text { (se }\end{array}$ & Uptime & $\begin{array}{c}\text { SRTT } \\
\text { (ms) }\end{array}$ & RTO & $\begin{array}{c}Q \\
\text { Cnt }\end{array}$ & $\begin{array}{l}\text { Seq } \\
\text { Num }\end{array}$ \\
\hline 0 & 192.168 .1 .2 & $\mathrm{Se} 3 / 0$ & 11 & $00: 07: 20$ & 40 & 1000 & 0 & 15 \\
\hline 1 & 192.168 .1 .193 & $\mathrm{Se} 2 / 0$ & 13 & $00: 07: 18$ & 40 & 1000 & 0 & 15 \\
\hline
\end{tabular}

Gambar 15. Waktu konvergensi hasil simulasi Topologi Ring EIGRP

Pada Gambar 19. dapat dilihat di kolom Hold (sec) dimana kolom tersebut menunjukan Hold time pada router untuk menunggu packet Hello dari router yang lain waktu inilah yang mendasari waktu konvergensi di setiap routemya dimana Hello interval secara default yaitu 5 detik dan Hold/Dead interval secara default yaitu 15 detik. Sehingga waktu rata-rata konvergensi untuk setiap router adalah:

$$
\text { Waktu Konvergensi Rata }- \text { rata }=\frac{13+13+11+14}{4}=12,75 \text { detik }
$$

b. Waktu konvergensi Topologi Mesh EIGRP

Untuk mengetahui waktu konvergensi Mesh EIGRP dapat dilakukan dengan cara perintah "show ip EIGRP neighbors" pada CLI Command di setiap routernya yang hasilnya seperti berikut:

$$
\text { Waktu Konvergensi Rata }- \text { rata }=\frac{14+14+13+11}{4}=13 \text { detik }
$$

c. Waktu konvergensi Topologi Ring OSPF

Untuk mengetahui waktu konvergensi Ring OSPF dapat dilakukan dengan cara perintah "show ip OSPF neighbors" pada CLI Command di setiap routernya yang

\begin{tabular}{|c|c|c|c|c|c|c|}
\hline Neighbor ID & Pri & State & & Dead Time & Address & Interface \\
\hline 3.3 .3 .3 & 0 & FULL/ & - & $00: 00: 31$ & 192.168 .1 .2 & Serial2/0 \\
\hline 1.1 .1 .1 & 0 & FULL/ & - & $00: 00: 32$ & 192.168 .1 .193 & Serial3/0 \\
\hline
\end{tabular}
hasilnya seperti berikut:

Gambar 16. Waktu konvergensi hasil simulasi Topologi Ring OSPF

Pada Gambar 16. Dapat dilihat di kolom Dead Time dimana kolom tersebut menunjukan Dead Time pada router untuk menunggu packet Hello dari router yang lain waktu inilah yang mendasari waktu konvergensi di setiap routemya dimana Hello interval secara default yaitu 10 detik dan Hold/Dead interval secara 
default yaitu 40 detik. Sehingga waktu rata-rata konvergensi untuk setiap router adalah:

$$
\text { Waktu Konvergensi Rata }- \text { rata }=\frac{32+32+36+38}{4}=34,5 \text { detik }
$$

d. Waktu konvergensi Topologi Mesh OSPF

Untuk mengetahui waktu konvergensi Ring OSPF dapat dilakukan dengan cara perintah "show ip OSPF neighbors" pada CLI Command di setiap routernya yang hasilnya seperti berikut:

$$
\text { Waktu Konvergensi Rata }- \text { rata }=\frac{32+36+39+34}{4}=35,25 \text { detik }
$$

\section{KESI MPULAN}

Hasil dari pengujian jaringan topologi Ring dan Mesh pada routing protokol EIGRP dan OSPF diperoleh kesimpulan sebagai berikut:

a. Pada pengujian topologi Ring nilai delay total EIGRP lebih baik $386 \mu$ detik dibandingkan nilai delay pada OSPF.

b. Pada pengujian topologi Mesh nilai delay total OSPF lebih baik $453 \mu$ detik dibandingkan nilai delay pada EIGRP..

c. Untuk topologi Mesh, OSPF bekerja lebih baik karena dapat memilih hop terpendek dibandingkan dengan EIGRP pada bandwidth yang sama hal ini dikarenakan perhitungan nilai Cost yang lebih sederhana dibandingkan perhitungan nilai metric EIGRP.

d. OSPF bersifat link state sehingga pada nilai Cost yang sama paket akan dikirimkan tidak selalu pada rute terpendek tapi juga rute terpanjang.

e. Waktu konvergensi Rata-rata pada Topologi Ring EIGRP adalah 12,75 detik dan pada Topologi Ring OSPFadalah 34,5 detik.

f. Waktu konvergensi Rata-rata pada Topologi Mesh EIGRP adalah 13 detik dan pada Topologi Mesh OSPFadalah 35,25 detik.

g. Waktu dead interval EIGRP adalah 15 detik sedangkan OSPF adalah 40 detik sehingga waktu konvergensi EIGRP lebih cepat dibandingkan OSPF.

\section{DAFTAR RUJ UKAN}

Sofana, Iwan. (2012). CISCO CCNP dan Jaringan Komputer (Materi Route, Switch, \& Troubleshooting). Bandung: Informatika.

Dwipa Rosada, Ferdian. (2011). Simulasi Komunikasi Data Pada Jaringan Ethernet berdasarkan Spanning-Tree Protocol (STP) menggunakan Cisco Packet Tracer 5.3. Bandung: ITENAS.

Adi Purwanto, Agung. (2007). Perancangan dan Simulasi Jaringan Fast Ethernet dengan Menggunakan Routing Protocol OSPF dan EIGRP. Depok: Universitas Indonesia.

Nazrul, Muhammad. (2010). Simulation-Based Comparative Study of EIGRP and OSPF for Real-Time Applications. Karlskorna: Blekinge Institute of Technology.

P, Ramya. (2012). Implementing OSPF Protocol In CISCO 2800 Series Router. Coimbatore: International Journal of Innovations in Engineering and Technology (IJIET) Vol 1. SNS College Of Engineering.

Sofana, Iwan. (2010). CISCO CCNA \& Jaringan Komputer. Bandung: Informatika. 